\title{
The state of pensions
}

Received: 11th October, 2000

\section{Eileen Imrie}

is originally from Glasgow, educated both in Scotland and Canada. She has been in the pensions industry for over 20 years and has worked for insurance companies, IFAs, a stockbroker and specialist pension practitioners. She left Scotland in 1992 and joined Carr Sheppards to set up the administration department for their SIPP and SSAS products. She was recognised as a Pensioneer Trustee in 1996 and has been Secretary to the SPG since 1995. On leaving Carr Sheppards in 1997 she joined Pointon York and has just moved to Pimco Trustees Limited in Redhill, Surrey.

\begin{abstract}
The aims, objectives and subject matter of this paper are recent developments, current areas of discussion, future trends and areas of concern relating to the legislative framework of pensions. Comments are made on personal and occupational schemes, money purchase and final salary schemes plus insured and self-insured schemes.
\end{abstract}

Keywords: pensions; legislation; stakeholder; the future

\section{Introduction}

Imagine being given a blank sheet of paper and asked to design a new structure for retirement provision (even if the phrase 'for the New Millennium' was attached to the brief by some politician). Given the degree to which different types of jobs and different career patterns are becoming important to more and more people, it would probably never be practical to adopt a 'one size fits all' approach; a computer contractor who stayed with each client less than a year and earned $£ 200,000$ a year would probably never be happy with the pension arrangements appropriate to a primary school teacher who spends her entire career earning less than $£ 20,000$ at a small school in Skye. However, unnecessary complexity in structure and regulation could be avoided.

Pension schemes would probably be

Eileen Imrie

Pimco Trustees Ltd, The Old Tannery, Oakdene Road, Redhill, Surrey RH1 6BT.

Tel: +44(0) 1737779 939; Fax: +44(0) 1737778656 divided into defined contribution and defined benefit schemes. Defined contribution schemes would have strict limits placed on how much could be paid into them, but no overall limit on what could be taken out, though the Government's desire to maximise tax revenues would probably mean that tax-free cash from pension schemes would continue to be restricted. Defined benefit schemes would, of course, have strict restrictions on how big the benefits could be and how and when they were taken, but there seems little need also to restrict what is paid in. There would need to be restrictions on transfers between the two regimes and on those who wished to adopt a 'mix and match' approach in an attempt to take advantage of the system. The prevention of abuse would also mean it would be necessary to have some constraints on investments, accounting standards and so on.

Since tax relief on contributions and 'tax-free' growth inside the fund are only being offered by the Government because they want to ensure that people can support themselves in retirement without any reliance on the State, there would inevitably be some restrictions on when and how benefits could be taken. For the same reason the Government 
would also probably feel little need to ensure that the director of a $\mathrm{Plc}$ who earns $\mathcal{K}^{500,000}$ a year continues to make full pension provision. His doing so neither saves the Government money later nor gains votes now, so some restriction on maximum benefits or contributions will probably remain inevitable. Nevertheless, this does not mean that the current 'earnings cap' would be regarded as being at the correct level if starting from scratch, and basing some tests on half the 'earnings cap' as a definition of a high earner (as the new draft regulations initially proposed) would surely not be regarded as sensible by anyone.

Since those with the greatest need to make provision are by definition not those with the greatest capacity to do so, the system would probably be structured so as to maximise the individual's ability to make up later in life for not having contributed fully before. Of course, carry-forward provisions and continuous service provisions offer just this at the moment, but from 6th April, 2001 carry-forward will be abolished. This will mean that an individual who is unable to maximise their contribution early in their career will never be able to make good the shortfall, thus minimising the amount of tax relief the Government needs to give them today and maximising the chances of becoming a burden on the State in the future. If someone were designing a system from scratch, such short-termism would not be appropriate. Indeed, a case could easily be made for permitting carry-forward for employer contributions and for publicising the attractiveness of this opportunity.

\section{Complications}

Of course, there would be still be some complications, on transfers between regimes, pension splitting on divorce, income drawdown (though a rule forcing annuity purchase would surely never be considered today if it did not already exist) and so on. Nevertheless, defined contribution schemes would look very similar to a PEP or ISA and two-thirds of the rulebook currently applying to them would be thrown away. Those still fortunate enough to be a member of defined benefit scheme (like those at the Inland Revenue, PSO and judges) would probably feel little effect unless or until they transferred to another type of pension scheme and/or employment, but their scheme administrator would have a much lower administrative and regulatory burden.

Sadly, no one has thrown away the old rulebook for all kinds of pension schemes before attempting to write a new one for 30 years. Instead they have simply added a new set of rules to the old set, frequently applying several layers of new rules to old schemes. At its most basic, this has increased charges, confusion and the possibility of conflicting pieces of legislation. Those in the pensions industry may find the situation confusing and time-consuming, but at least it keeps them all in work. For the people whose retirement provision they are attempting to secure, there is no such advantage from the books and books of rules. Unsurprisingly, they find pensions as clear as mud and about as interesting, and understandably probably have a low opinion of those in the pensions industry.

\section{New rules}

So, if the above describes in brief the pensions world as the author would like to see it, it is probably worth contrasting this with what is actually happening as the latest new layer of rules get applied, and the next set can be seen appearing around the corner. 
New rules have been introduced primarily under two broad categories: Stakeholder and The Welfare \& Reform Pensions Act. Stakeholder not only covers the rules and regulations of this variant of Personal Pensions, but also includes the end of carry-forward and waiver of premium inside a pension contract, together with new constraints on life assurance benefits. There are also new considerations as to which pensions regime is most appropriate for which pension scheme, and over the interaction between Stakeholder and state benefits.

At the same time, the Welfare \& Reform Pensions Act increased the regulatory burden on the trustees of pension schemes, changed the rules on bankruptcy and brought in the major pieces of legislation required for pensions on divorce and pension splitting. Not all of these changes are bad things, of course, but it does not end here.

The Welfare \& Reform Pensions Act has resulted in the formalising of the protections afforded to member's benefits on bankruptcy, either as a company or an individual. It may seem less than perfect that there are circumstances under which a divorcing partner can get some of a member's pension benefits while his defrauded creditors cannot, but at least occupational and personal pension schemes are now equivalent in their safeguarding of a member's rights, and everyone knows where they stand and do not need a court to decide.

On pensions on divorce and pension splitting the rules have now been issued. There are several areas requiring interpretation and further clarification, particularly with defined benefit schemes, but at least the regulatory structure within which everyone has to work is now in place. While clarifying what the rules are in these areas has been a major achievement, the picture is still not clear and few in the industry would regard as helpful the substantial increase in the administrative, reporting and regulatory burden brought in by all of these changes to legislation. Not only do these changes increase the work for an employer and the trustees of the pension scheme, they also make the penalties for errors much more serious. Furthermore, breaches of rules on Personal Pension Plans can now have a dramatic effect, with the individual's scheme being disqualified and a tax charge imposed of 40 per cent. For all kinds of scheme, the cost of administration and the cost of mistakes are rising rapidly, and the smiles of the lawyers are getting wider.

While discussing the weaknesses of the new legislation, it is also worth mentioning the new income drawdown rules for occupational schemes (not, of course, to be confused with the old SSAS rules), which are in several respects less attractive than income drawdown under personal pension schemes. However, assessing which is the best approach in the real world for an individual is still far from straightforward. Meanwhile, self-assessment has been introduced for everyone and has been a great success, with only around a quarter of the tax calculations performed by the Inland Revenue in the self-assessment regime being completely wrong! Bolstered by this enormous success, self-assessment was introduced for SSAS. Without wanting to appear overly negative, it has been a shambles. Self-assessment for SIPP is under negotiation and the outcome is awaited with bated breath.

\section{Gild yields}

While it is very easy to focus entirely on the changes to legislation, one of the most important changes of all has been the collapse in gilt yields. The changes to interest rates and inflation that have 
been seen in the last few years, along with Euro considerations, explain the collapse in gilt yields, but the fact remains that no one in the industry or Government bodies expected it. Indeed, the introduction of MFR (Minimum Funding Requirements) for occupational pension schemes increased the demand for gilts at exactly the same time that improving Government finances reduced the supply of gilts, making this fall in yields even more dramatic.

This change has meant that many investors have seen their pension fund rise in value over the last few years, only to find that the maximum pension payment has fallen, whether they are purchasing an annuity or taking maximum benefits under income drawdown. However, the collapse in inflation and the increase in fund values and transfer values together mean that most pension contracts will produce a level of index-linked income not radically different from that which would have been expected. As a result, many people who would choose to buy an index-linked annuity to protect them from inflation have gained on the swings much of what they lost on the roundabouts.

By contrast, income drawdown rules fix maximum and minimum income levels with reference to straight gilt yields, just like a level annuity would do. This is unfortunate, because falling inflation has meant that level annuities and straight gilt yields have collapsed, making a mockery of previous calculations. Furthermore, those with small pension funds are typically most likely to buy a level annuity, as they need the maximum income possible from their limited resources and therefore the collapse in gilt yields has hit them particularly hard. On the other hand, those with larger funds might well have had the luxury of being able to consider an index-linked annuity, where rates have fallen much less dramatically, yet the fact that GAD tables are based on straight gilt yields means that these very people, clearly those most likely to consider income drawdown, are also being substantially affected.

\section{Further legislation}

All of the above is now in law whether people like it or not, but there are further major additional pieces of legislation on the horizon. Some providers/insurance companies were delighted by the fact that legislation used to forbid the transfer of monies between schemes once income drawdown had begun, as this guaranteed that they would keep the member's assets from the day he took his benefits under income drawdown until the day he purchased an annuity, no matter how bad the investment performance or administration. Indeed, many SIPP providers regarded this as a major sales point, as a member did not have to commit to decades of their investment management as well as their pensions administration. This restriction is now being removed and members should be able to transfer benefits between providers/insurance companies right up to the point of annuity purchase. Providers will therefore have to justify keeping members money by good administration and/or good investment performance. In addition, the need for segmentation under personal pensions will disappear as gradual withdrawal of benefits is now possible and it is intended to have one single reference date for the triennial review as applies to income drawdown when a member has chosen essentially to take phased retirement. All of these changes should help scheme members.

Worryingly, the new draft regulations 
appeared to require prompt reporting to the PSO of every investment transaction on every SIPP. However, many in the industry, including the author believed that this would be impractical, and it is really intended to cover reporting on properties and borrowings and this appears to be the case. While there are high hopes that the reporting requirements will turn out to be sensible and not onerous, no such comments can yet be made about the proposed new transfer regulations. These appear to introduce a statutory basis for calculating permitted transfer values from occupational schemes, but as they are currently proposed the effect would be to reduce by up to two-thirds the transfer value that could be paid. Since the value of the benefits in the existing scheme would, of course, not have changed, this is only one step removed from making all transfers illegal, as it would almost make it impossible ever to recommend a transfer.

Nor is this all. The new draft rules introduced without warning a new level of income above which the full GN11 test must be applied on transfers. This would have meant that those who have earnings higher than half the 'earnings cap' will be subject to a GN11 test on transfer, whereas the equivalent figure today is the full 'earnings cap'. However, this has subsequently been removed. While it can be assumed that it is not the PSO's intention to make transfers between pension schemes impossible, the pensions industry waits and hopes for further clarification on their actual intent. Apart from anything else, Stakeholder rules appear to permit a SSAS to change regimes to a defined contribution scheme, under the definition of Stakeholder, without any transfer tests being applied, irrespective of the fund size. This does not appear consistent with the above position on individuals transferring, and appears to leave the door wide open to abuse.

Practical problems applying the MFR rules and the reaction of employers to increasing funding rates (ie, shutting their final salary schemes) together mean that the rules on MFR are under review. Indeed, Gordon Brown's budget statement appears to agree with the Myners Report that the MFR should be abolished. Meanwhile, the debate continues on the old problem of forced annuity purchase at age 75 . Few people can see why every member of a defined contribution scheme should be forced to buy an annuity by age 75 , thus potentially donating their entire fund value to an insurance company and the tax man, though annuities certainly have their attractions and can suit many members' individual requirements.

\section{Early retirement}

Another area of hot debate is early retirement. It seems iniquitous to many people that a director of a Plc can take early retirement and receive his benefits, probably taking a large tax-free cash sum, and then return to work for the same employer the next day, and a self-employed person (like a senior partner of a solicitor's practice) can do the same. Contrast this with a member of a SSAS, who will find that the PSO have reserved the right to tax his tax-free cash as they insist that in this case alone the member has not retired, basing this on their current interpretation of the rules, not upon past circumstances or statute. The only way that these inconsistencies could possibly be avoided is to have a single statutory definition of retirement, but there is no sign of one on the horizon yet. 


\section{Stakeholder}

Turning attention to the brave new world of Stakeholder pensions, it is probably worth pointing out that Stakeholder benefits will be included when assessing means-tested benefits. Combining this with the new Minimum Income Guarantee for pensioners could mean that those who do not currently have a pension scheme could be well advised to avoid Stakeholder entirely. Why would anyone contribute to a pension arrangement to give them, say, an extra $\mathcal{K}^{50}$ per month at retirement, if the operation of the minimum income guarantee simply means that they lose other benefits with exactly the same value? So a man of, say, ,50 with $^{5}$ modest earnings may well find contributing to a Stakeholder pension to be completely unhelpful. Contrast this with his chief executive's wife and children, who will be able to obtain full tax relief on contributions to Stakeholder, even if they have no need for retirement provision and no earnings and have never worked.

It might appear that the above suggests that taxes are being spent on providing marginal benefits for the rich, while it is being claimed that they are providing improved retirement benefits for the needy. However, cynicism on this point is probably dwarfed by the cynical reaction of many commentators to the abolition of ACT (Advanced Corporation Tax) a couple of years ago. To recap, when a UK company paid an $80 \mathrm{p}$ dividend, a basic rate taxpayer would be deemed not to have a tax liability (as the company had already paid it through their tax bill), so the $80 \mathrm{p}$ dividend was worth $80 \mathrm{p}$. A higher-rate taxpayer would be deemed to have the same tax credit as the basic rate taxpayer (ie, 20p) and would therefore have a further $20 \mathrm{p}$ liability, meaning that they ended up with $60 \mathrm{p}$. Those who were not deemed to have a UK tax liability could reclaim the tax credit in full. Hence, pension schemes, charities and those whose income was so low they paid no tax would get the full benefit of the net $80 \mathrm{p}$ dividend and the $20 \mathrm{p}$ tax credit that was deemed to have been paid already, making a total of $100 \mathrm{p}$.

As readers will remember, Gordon Brown decided to abolish ACT so as to boost long-term investment! Now the basic rate taxpayer still ends up with $80 \mathrm{p}$ and the higher-rate taxpayer with $60 \mathrm{p}$. However, the pension fund, the charity and the non-taxpayer cannot get back any of the tax that is deemed to have been paid. Thus they have seen one fifth of their income disappear into the coffers of the Treasury, while taxpayers have suffered no such loss. Given that pension schemes own nearly half of the UK Stock Market and are by far the largest investors in the UK, and are by their nature long term, this amounts to attempting to stimulate investment by taxing it.

Imposing the same burden of taxation (in respect of investment income) on an individual earning $£ 30,000$, an individual earning $\mathcal{E}^{3}, 000$, Oxfam, the Imperial Cancer Research Fund and every pension scheme in the land seems difficult to square with the stated aims of the Government. Even if it is accepted that there is a benefit to the country to be obtained from this measure (apart from raising tax revenue and people not realising where it came from until it is too late), giving $10 \mathrm{p}$ of the tax credit back to those in PEPs and ISAs (which can be encashed tomorrow) and not giving it to pension schemes (which are most obviously long-term savings for retirement), or to charities, appears difficult to explain. Perhaps the author is just an optimist, but she would like to see the burden of taxation on pension funds, charities and the very poorest in 
society no higher under the next Labour Government than it was under the last Conservative Government. If that means that the rich have to pay a little more tax, many people would accept it. The author, for one, is happy leaving the fight for the rights of 40 per cent taxpayers to others.

\section{Conclusions}

Pensions are never going to be really simple, and it is probably too late to persuade people to adopt the approach of throwing away the rulebook and starting again. However, given the rapid changes occurring in the marketplace, it is vital to keep on top of the detail so as to ensure giving appropriate advice to clients. It is also vital to continue to study proposals as they come out in order to assist the PSO etc, in achieving their aims without unintentionally damaging existing and future pensioners further. Finally, there is also a duty on all of us to continue to highlight the more unfortunate decisions of Government and their actual ramifications, while bearing in mind the principle upon which everyone agrees (even the Government), namely, that well-structured and well-funded pension arrangements remain the best way of safeguarding the future for everyone. 